\title{
The Dialogical Self: Converging East-West Constructions
}

\section{Commentary}

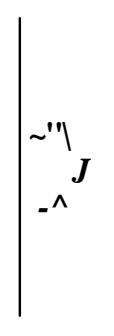

\begin{abstract}
Prompted by the work of Hermans, we attempt to construct the dialogical self informed by Eastern traditions. To describe dialogical phenomenology we turn to three resources: (a)

Chinese intellectual traditions, (b) dreams and (c) daily life. Dialogical attributes are described: the dialogical self is capable of polyvocality but also of achieving unity with diversity; metacognition is vital to its development. We attempt to clarify the relation between dialogics and dialectics: The dialogical self is capable of taking an active part in the interaction between inner and outer dialectics, and hence of participating in its own creation and transformation. Finally, we illustrate how the study of dialogical movements may be operationalized.
\end{abstract}

Key Words Chinese, dialectics, dialogical, metacognition, relationalism, self

\author{
David Yau-fai Ho and Shui-fun Fiona Chan \\ National Institute of Education, Singapore
}

Si-qing Peng

Peking University, China

Aik Kwang Ng

National Institute of Education, Singapore

\section{The Dialogical Self: Converging East-West Constructions}

The East and the West appear to resonate in current conceptions of the self. In the East, conceptions grounded in a worldview that stresses the relational character of human existence have always been dominant. Methodological individualism is alien to Eastern intellectual traditions, and thus relational constructions of selfhood come naturally. In the West, there is growing awareness of the tension between two conceptions: The first, rooted in individualism, is that of the autonomous self; the second, more relationally and socially concerned, is that of the self conceived in terms of engagement with others. For convenience, we may term the first an individualistic and the second a relational conception. Long eclipsed by the individualistic, the 
relational conception is now demanding to be heard.

Against this backdrop, Hermans' (1999, 2001a, 2001b) work represents a contemporary construction of relational selfhood in the West.

Culture \& Psychology Copyright $\odot 2001$ SAGE Publications (London, Thousand Oaks, CA and New Delhi) Vol. 7(3): 393-408 [1354-067X(200109) 7:3; 393-408; 018673] 
His dialogical self weaves together the conceptions of dialogue according to the Russian school of Bakhtin (1929/1973) and of the self emanating from American theorists such as William James, George Herbert Mead and Gordon Allport. Hermans (1999, 2001a) describes the dialogical self in terms of a dynamic multiplicity of relatively autonomous $I$-positions. The $I$ has the capability to move spatially from one position to another according to situational and temporal changes. It may fluctuate among different and even opposed positions. Hermans' dialogical self is thus characterized by temporal as well as spatial (positional) features. This view of multiplicity of positions, or decentralization, also extends to the conception of culture (Hermans, 2001a). Thus, Hermans challenges both the idea of a core, essential self and the idea of a core, essential culture.

Hermans (1999) describes dialogical movement in terms of a three-step model: (a) positioning, where the self takes a position; (b) counterpositioning, where the voice of a real or imaginary other (or of oneself) speaks from a counterposition; and (c) and repositioning, where the self reformulates its original position. Self-innovation is achieved if the successive steps are associated with increasingly higher levels of novelty. Subsequently, Hermans (2001b) presents a more general method, called the Personal Position Repertoire, for research and practice. This method may be applied to study dialogical movement in dyadic interactions.

It occurs to us that, despite differences in terminology, Hermans' work resonates with current constructions of selfhood informed by Eastern intellectual traditions. One such construction is the self-in-relations by Ho, Peng, Lai and Chan (in press). Ho et al. strive to meet two explicit requirements: (a) inclusion of both self-in-other and other-in-self; and (b) to be faithful to a conception of human nature that gives full recognition to the whole range of capabilities and potentialities unique to humans. We submit that the same two requirements would apply no less to any construction of the dialogical self. The first follows from the dialectic between selfhood and otherness: self and other are inextricably intertwined; each derives its meaning from the coexistence of the other (cf. Cooley, 1902/1964). The second follows from recognizing the importance of cognitive capabilitiessuch as the capacity for self-consciousness, other-consciousness and metacognition-for the emergence of selfhood. Comparing Hermans' dialogical self and Ho et al.'s self-in-relations reveals a common ground with respect to these two requirements. An appreciation of this common ground provides a convenient point of departure for our present attempt to construct the dialogical self. 
Constructing the dialogical self brings together two cardinal ideas, dialogue and self, integrating them into a single construct. A clarification of the terminology is needed at the outset. The word dialogical means 'relating to', or 'characterized by dialogue'; it is usually meant to refer to a conversation between two or more people-that is, external dialogue. However, in the context of self psychology, dialogical refers no less to internal dialogue-a person 'talking with him- or herself (see Bain, 1996, pp. 214-216, for a discussion of the terminology regarding 'self-talk'). The idea of talking with oneself is likely to invite an association with egocentric speech. However, in adults there is no necessary association (or lack of association) between egocen-tricity and internality-externality One may be egocentric while engaged in a dialogue with others, or empathic while engaged in a dialogue with oneself. This is not to deny that there may be qualitative differences between internal and external dialogues. We use the term internal dialogue (or self-directed dialogue), without prior theoretical commitment, to refer simply to intrapersonal dialogue-that is, dialogue directed to oneself, involving only one person, acting as both 'speaker' and 'listener'. External dialogue (or other-directed dialogue) is interpersonal, referring to dialogue that the self engages in with other(s) — with the self still being the point of reference.

This apparent simplicity of the idea of dialogue is deceptive, for complicated questions immediately arise. Who are the interlocutors? Are they subordinate to a unified self? What do internal dialogues tell us about the nature of human cognition? Our present purpose is to delineate the nature and characteristics of dialogues, whereby we may gain a better understanding of selfhood.

\section{Dialogical Phenomenology}

To construct the dialogical self informed by Eastern intellectual traditions and meet our two stated requirements above is a formidable challenge. First, to explore dialogical phenomenology, we turn to three resources: (a) Chinese intellectual traditions, (b) dreams and (c) daily life.

\section{Chinese Intellectual Traditions}

Chinese philosophical, particularly Daoist (Taoist), ${ }^{1}$ and literary traditions are a source of inspiration. A tale relates that Zhuangzi (Chuang-tzu) once dreamt that he was a butterfly and was happy as a butterfly, not knowing that he was Zhuangzi. When he awoke, he did not know whether it was Zhuangzi dreaming that he was a butterfly 
or a butterfly dreaming that it was Zhuangzi. In an exchange with his intellectual companion about the happiness of fish, Hui Shi (Hui Shih) challenged Zhuangzi: 'You are not a fish. Whence do you know the fish are happy?' Zhuangzi retorted: 'You are not me. Whence do you know that I don't know the fish are happy?' The military strategist Sunzi (Sun-tzu) stated: 'Know yourself and your adversary and be not imperiled in a hundred battles.' The novel Romance of the Three Kingdoms contains a famous passage in which Kong Ming (Kung Ming), another renowned military strategist, calculated his adversary's calculation that took into consideration Kong Ming's own 'cunning' (an instance of meta-metacognition), and predicted accurately the course of action that his adversary took. The great writer Ouyang Xiu (Ou-Yang Hsiu) wrote: 'Beasts and birds know the delight of wooded hills, not the delight of people. People know the delight of being the Governor's [referring to Ouyang Xiu himself] sight-seeing companions, not the Governor's delight in their delight.' This brief excursion into Chinese traditions reveals the workings of metacognition in dialectical thinking. The famous tale about Zhuangzi's dream, in particular, suggests an avenue par excellence for exploring the dialogical self.

\section{The Phenomenal World of Dreams}

In dreams, the self makes its phenomenal appearance in variegated formsall under observation by itself, the dreaming self-as-perceiver. It may appear as the dreamer him- or herself, in an active or a passive role. The dreamer may act as an agent, actively participating, even directing the course of events, in the dream. At other times, the dreamer simply observes what is going on without intervention-like the passive, uninvolved self-as-witness. The self may split itself into different selves, engaged in a dialogue with one another. When it does, the self-as-perceiver may obtain a glimpse into various (e.g. ideal, rejected and hidden) aspects of its selfhood revealed through these different selves. Or the self may appear in the guise of others or even of nonhuman things engaged in a dialogue among themselves or with the dreamer him- or herself. When it does, the self-as-perceiver may observe its own self looking at itself and others, as well as its own self and others being looked at by others. These selves and others come and go, often in quick succession, seemingly in a random fashion. They may shift, or even interchange, their positions - in a manner of role reversals. Dreams within a dream may be experienced, as Zhuangzi observed in his philosophical reflections centuries ago. Sometimes, while dreaming the dreamer-as-subject even reminds the 
dreamer-as-object that it is only a dream. This exploration of oneiric phenomenology serves to illustrate the richness and complicated nature of internal dialogue.

\section{Dialogical States in Daily Life}

Internal dialogue does not take place only in dreams, while sleeping or daydreaming; it is an integral part of daily living. It may serve self-guiding, self-consolation, even self-healing functions. We fall into internal dialogical states, without conscious effort, as readily as we walk. 'Absent-minded' professors may be seen talking with themselves, dead serious in their quest for a solution to some intriguing problem. We may be self-absorbed and wish to retreat into our private selves, undisturbed by others. We may be alone or socially deprived, and feel the need to talk with ourselves. Or we may feel that we are not being heard or understood. The following verse captures the resulting sense of frustration:

I speak; the spoken words hit a wall.

I swallow the unspoken, that yearns to be heard.

In social interactions, we engage in internal dialogue to serve as a social compass with which to guide our actions. Internal dialogue plays a key role in bidirectional social calculations: we assume that our actions and thoughts are considered by others; likewise, we also assume that others assume that their actions and thoughts are considered by us (cf. Ho et al., in press). In other words, we must grant internal dialogue to others, no less than to ourselves, in order to act effectively-as illustrated in the story of Kong Ming recounted above. Nowhere is this bidirectional process more alluring, and precarious, than in the case of two lovers, each of whom is uncertain about the other's feelings and intentions and neither of whom has yet decided to make a declaration to the other.

Internal dialogue may be overt (spoken aloud) or covert (silent). Overt internal dialogues, in most social contexts, invite suspicion of madness. So most of us learn to keep them covert, or explain to others present that we are merely 'thinking aloud'. We also learn to shift back and forth between external dialogue (which is overt, at least to the parties directly involved) and covert internal dialogue during social encounters. Indeed, inability to do so is indicative of psychopathology On the other hand, constantly keeping distance between external dialogue and covert internal dialogue means concealment, guarded-ness and a lack of trust. Happy are those couples when mutually the distance vanishes. 
In adulthood, most of us are able to shift effortlessly between internal and external dialogical states. We enter an internal state for self-guidance or selfconsolation. We leave this internal state when we need to give our undivided attention to external dialogue. Sometimes, we deliberately engage in external dialogue when internal dialogue leads to a dead end. So we seek otherconsolation or external reassurance, and talk with people whom we feel have an understanding ear. Even absent-minded professors suspend their selfabsorption and talk with their colleagues for help or inspiration to solve problems.

\section{Dialogical Attributes}

We may now have a better understanding of some basic attributes of the dialogical self, and answer the questions we raised above.

\section{The World of Interlocutors-in-Relations}

The interlocutors of internal dialogue are many, including different selves of the same person and other actors, actual, imaginary or implied. One might claim that they are more multifarious than those of external dialogue, where normally the self does not split into different selves. The phenomenal world of the dialogical self is thus alive with selves and others interacting directly or indirectly with one another in a multiplicity of relationships. It is a dynamic field of forces and counterforces generated by, and acting upon, the dialogical self. At the same time, the dialogical self responds to these forces, transforming itself anew.

The dialogical self is extremely adept at looking at the interlocutors, that is, at itself and others, directly or indirectly through the eyes of others. So much so that not even Hilgard's (1949) metaphor of mirrors in a barber shop may suffice in capturing its social essence. When others are absent, the metaphor provides only an analogy of the solitary self taking a look at itself, and being looked at by itself, ad infini-tum. Adding the presence of others in the mirrors would capture more fully the richness of the dialogical self. At the beginning of the 20th century, Cooley (1902/1964, p. 184) represented one of the early theorists in the West who accorded self-other interaction a prominent role in the conception of selfhood. He used the metaphor of the 'looking glass' to describe how we often see our reflections in the eyes of others, even imagine what they think of us.

Often the dialogical self-as-agent does not feel that it is in control of other actors or even of itself, or that it can direct the course of events. In this sense, the dream-like representation of reality may be illustrative. The author of the dream-plot is unknown. The manner and order 
in which the different selves and other actors make their appearance do not seem to be under control by anyone. Often the appearance is unexpected and uninvited, under strange or exotic circumstances. The selves and actors behave like autonomous characters, with their own independent volition and voices, in rather unpredictable ways. The flow of events seems uncontrolled and uncontrollable. All these may leave the dreaming self-as-agent with a sense of frustration, even helplessness.

In a similar vein, freedom from univocal control is a basic idea underlying Bakhtin's (1929/1973) conception of dialogue. Inspired by the works of Dostoevsky, Bakhtin uses the metaphor of the polyphonic novel, in which the characters are ideologically autonomous; not treated as 'obedient slaves' in the service of the author's intentions, they are capable of standing beside, disagreeing, even rebelling against their creator. There is a decentralized plurality of consciousness, represented by different voices expressing their own ideas. These voices have different spatial positions, accompanying and opposing one another in a dialogical relation. Thus, there is no unified world envisioned by the author to which the voices are subordinated.

We may extend Bakhtin's conception to writing in general. To many people, writing is arduous, even tortuous. Writing would be simple if it were merely a matter of putting into words one's thoughts. It is anything but simple when the writer engages in self-reflective scrutiny of what he or she has committed in writing, that is, critical internal dialogue-questioning, doubting, arguing. Each statement written down generates counterstatements. Self-reflective writing is thus characterized by polyvocality. It is more so when the writer anticipates how readers, especially critics, may react. Some experience what has been called writer's block or paralysis. We call it dialogical abyss: endless possibilities and branches of thought confronting, tormenting and, at the same time, alluring their creator. Eventually, after due assiduity and suffering, come closure and delight. Polyvocality would have then served its creative purpose. But some find it quite impossible to escape from the dialogical abyss. (When that happens, our recommendation is to engage in external dialogue - that is, seek someone therapeutic to converse with before resuming to write.) If this is descriptive of single authorship, we can imagine how much more complex the situation is in multiple authorship.

\section{Self as Diversity within Unity}

The theme of polyvocality touches one of the enduring issues concerning the nature of selfhood, namely the self as single versus 
multiple. This issue concerns the problem of how the diverse selves may be united into a single whole (see Paranjpe, 1998, for an in-depth treatment). Unity, continuity and self-sameness are usually thought of as attributes that define personal identity. In the West, the dominant view is that each individual has a unified, continuous and self-same identity. The self is sovereign, or at least should have a sense of mastery, in its own household. Having a sense of personal control is essential to the health of selfhood. In a healthy state, the self is stable over time; it is a coherent, integrated and unitary whole. It is individual, not dividual. Clearly, this view is at odds with that of the polyvocal self, which is suggestive of disunity, discontinuity and change. How can personal identity be preserved? In the extreme, the polyvocal self appears to be the antithesis of psychological health: unstable, incoherent, disintegrative.

Hermans (2001a) says that a combination of continuity (in line with William James) and discontinuity (in line with Bakhtin) is a feature of the dialogical self. In a similar vein, we address the issue of the self as single versus multiple by adopting a dialectical stance. The dialogical self presents a paradox of unity and diversity, being capable of experiencing both. Forces of diversity manifest in polyvocality pull the self in different directions; if unchecked, they threaten disintegration. At the same time, forces of unity work toward reintegration. Even in a dream, these forces may be seen to be at work. Sometimes, in the midst of dreaming, the dreamer feels that insight is gained from dialogues among selves and others. The voices seem to be informing the dreamer of things he or she has been only dimly aware of before, or of things he or she wants to but is afraid to hear. We have also mentioned that, on occasion, the dreamer is reminded of his or her dreaming. By whom? A daring, and controversial, answer is, in metaphoric terms, some behind-the-scene 'agent' who retains a measure of self-reflective capability. We say 'daring', because in principle the dialogical self-as-agent can never be directly observed. It is the percipient subject, not an object of perception (see Ho et al., in press, and Paranjpe, 1998, chap. 4, for an extended discussion of subject-object duality). At any instant, when perceived, it is no longer the percipient subject: the self-perceiv-ing-itself becomes the object perceived. Self-perception is, therefore, a subject-turned-object regress ad infinitum. In dreams, the subject-turned-object regress is particularly rich, offering us an opportunity to glimpse, if only indirectly, the elusive self-asagent.

A similar argument applies to writing. A writer will not complete the task of writing something coherent if there is no organizing 'sovereign' who eventually succeeds in gaining dominion over the 
different voices, each demanding to speak for itself independently. Dostoevsky's greatness lies in creating works of art in which diversity is given full expression through his polyvocal characters-and yet in the end these works of art bear his unique artistic signature. Unity again! The dialectical tension between unity and diversity is generative. For the dialogical self, new meanings and possibilities of action emerge through achieving dialectical synthesis, unity with diversity.

\section{The Nature of Human Cognition}

Exploring the dialogical self is informative of the nature of human cognition and, more generally, of mind. The capacity for self-consciousness has long been regarded as a necessary condition for the emergence of selfhood. We argue that the capacity for other-consciousness is no less a necessary condition. The idea that self and other each derive meaning from the coexistence of the other dates back to Daoist dialectics in ancient China. It also occupies a pivotal position in the theories of Charles Horton Cooley and George Herbert Mead. Selfhood and otherness thus imply each other. The appearance of self-consciousness and other-consciousness, conceived like twins (cf Cooley, 1902/1964), marks a qualitative quantum leap in the evolution of consciousness. The capacity for metacognition marks another quantum leap-this time exclusively in the human domain, for there is no evidence at all that nonhumans are capable of metacognition.

We argue that metacognition is vital to the development of the dialogical self. Consider the cognitive demands on the dialogue self to be aware of its relations with itself and with others. Metacognition is essential for the dialogical self to be aware of its ignorance, its own self-awareness, or its nonbeing. (We would argue that awareness of one's self-awareness is a necessary, but not sufficient, condition for awareness of one's nonbeing, which is more cognitively demanding.) It enables the dialogical self to contemplate the frightful consequences of losing its self-awareness or, in the extreme, of its very being, and to entertain possibilities of what it may become, never experienced before, in the future. As to its relation with others, the dialogical self has to be aware of a bidirectional process: how it reveals itself to others, as well as how its social image is perceived by others. (Cf. Ho et al., in press, on the self-in-relations.) It has to assess how accurately it perceives and is perceived by others. It must also deal with tensions that may arise from discrepant perceptions in this bidirectional process. Thus, metacognition renders new forms of thought and action possible for the dialogical self, in relations with both itself and others. 


\section{Dialogics and Dialectics}

The ability to engage in dialogue is a major cognitive achievement. However, it must not be thought that all thinking is dialogical, or that dialogues are necessarily dialectical, in nature. People differ greatly in their dialogical capability. At the negative pole is the inability to engage in any dialogue at all, a rather extreme form of cognitive impoverishment; less extreme, but still serious, is the inability to engage in dialogue at metacognitive levels. At the positive pole is the pinnacle achievement of dialectical thinking. Ho (2000) describes dialectical thinking as, above all, metacognitive-that is, thinking about the nature of thinking itself. The dialectical thinker is cognizant that human cognition is organized into systems and subsystems governed by the principle of hierarchical organization. Dialectical thinking emerges when one becomes aware of the manifold levels of complexity involved in human cognition, including one's own. Without such awareness, it remains a human potential unrealized. Dialectical thinking matures when it becomes metasystematic: The thinker systematically investigates the interrelations among constituent parts and part-whole relations within the organizational structure of cognition. Dialectical thinking does not negate, but presupposes, formal-operational thinking; it integrates formal-operational thinking within a more general cognitive system. Thus, formal-operational thinking is a necessary, but not a sufficient, condition for dialectical thinking. In sum, the dialectical thinker is most adept at shifting between levels of cognition within an organized whole; exploiting interaction between inner and outer dialectics to serve his or her ends; and dealing with polyvocality, absorbing and reorganizing different voices to achieve higher levels of integration. Dialectical thinking enables the dialogical self to reflect upon the nature of its existence, and thus to become cognizant of itself in relation to its non-self and of its place in society and the cosmos.

Dialogues, internal or external, seldom reach the level of fully developed dialectical thinking. At predialectical levels, dialogical thinking may not lead to the increase in novelty that has been theoretically anticipated. The empirical evidence is that, even among college students, the majority does not show an increase in self-rated novelty after being asked to think about a personal problem through a sequence of dialogical steps (Hermans, 1999, Table 2). We submit that two dialectical relations are particularly germane to self-innovation: one between inner and outer dialectics; and the other between thought and action. 


\section{Inner and Outer Dialectics}

Although we have dealt mostly with internal dialogue, a closer look at external dialogue is necessary. This brings us to the topic of interpersonal communication. Currently there are four major conceptions: the encoding/decoding, the intentionalist, the perspective-taking and the dialogical (Krauss \& Chiu, 1998). The most fundamental difference among these conceptions is perhaps where they locate meaning. The first three of the four conceptions may be characterized as individualistic, because they attempt to account for communication in terms of the mental processes of individual speakers and hearers. In contrast, the dialogical conception regards communication as 'a process in which participants work collaboratively to produce shared meanings’ (Krauss \& Chiu, 1998, p. 47).

In the parlance of dialectical psychology, internal dialogue, being a process internal to the individual, belongs to inner dialectics; external dialogue, being an interaction between the individual and its external world, belongs to outer dialectics. Dialectical psychology demands attention to the interdependence, as well as tensions and contradictions, between inner and outer dialectics. Inner dialectics is not just a reflection of outer dialectics; it has a selfgenerative capability, leading to new possibilities for thought and action. At the same time, outer dialectics is essential for consensual validation and is a source of nourishment for new ideas. Without consensual validation, inner dialectics would be autistic; devoid of new ideas, inner dialectics withers. Interaction between inner and outer dialectics creates the dialogical self. This conception is in line with the assumption that both interpersonal and intrapersonal processes are important for dia-logicality (Valsiner, 2000). Facilitated by both internal and external dialogues, the dialogical self creates, and is created by, its social environment. It acts on and changes the external world, transforming itself in the process. The theoretical import is that the dialogical conception ascribes a prominent role to inner-outer interactions in the construction of selfhood, and indeed of mind.

\section{Thought and Action}

Another fundamental difference between internal and external dialogues is that the former belongs to the domain of thought, whereas the latter belongs to the domain of action (as when we act to talk with someone). This leads us to consider more generally the reciprocal influence between thought and action-again, an interaction between inner and outer dialectics. This dialectical conception is embodied in Mao Zedong (Mao Tse-tung) Thought. In Mao’s conception of human 
nature, humankind is distinguished from all other things by virtue of its zijue nengdong xing (Ho, 1988), which we translate as the capacity for selfreflective activity. This capacity refers to active consciousness - the human propensity to take initiatives, purposefully and self-reflectively. It is manifest in two cognitive stages: the first leading from practice to knowledge, and the second leading from knowledge back to practice. To Mao, the second stage is more important than the first, for it alone can prove the correctness or incorrectness of the first. His central point is that correct ideas come from social practice, and from it alone. Together, the two stages enable human beings to formulate plans for action based on summation of experience, and test if their action succeeds in meeting anticipated results.

The dialogical self is thus capable of taking an active part in the interaction between inner and outer dialectics, and therefore of participating in its own creation. Prompted by Mao, we offer here a more detailed account of the dialectical relation between thought and action in terms of the following steps:

1. Learn from accumulation and summation of experience.

2. Formulate a plan for action.

3. Act according to plan.

4. Evaluate and reflect on the action taken (consequences, effectiveness, etc.).

5. Reformulate plan for action.

6. Act according to reformulated plan.

7. Learn from newly gained experience.

These steps constitute only a segmental description of the dialectic. In actuality, the cycle of thought-action-thought never ends, as long as there is life. And although most people think of thought as preceding action, it is not necessarily the case. Thus, we could have chosen action-thought-action as the basic cycle instead.

\section{Dialogical Movement: From Conceptualization to Operationalization}

\section{Methodological Principles}

The preceding analysis suggests several guiding principles in developing a methodology for studying dialogical movements:

1. Dialogical movement consists of cycles of positioning-counterpositioning-repositioning. Polyvocality may entail multiple dissenting voices (counterpositioning) coming from one's own different selves or from others, real or imaginary. Unity with diversity is achieved 
through a process of cognitive integration-disintegration-reinte-gration.

2. A full account of dialogical movements includes interactions between inner and outer dialectics: between internal and external dialogues, and between thought and action.

3. Individual differences in cognitive organization, metacognition in particular, should be considered. Following Ho et al. (in press), we may index complexity in terms of levels of perception or cognitive construal, using the sentence as a basic unit. Thus, self-perceptions, otherperceptions (i.e. perceptions of other people) and perceptions of relationships are first-level perceptions (L1); metaperceptions are secondlevel perceptions (L2); perceptions of metaperceptions are third-level perceptions (L3); and so forth.

In short, any perception may be itself the object of a higher-level perception. Higher levels of complexity are indicative of a greater dialectical, and hence dialogical, capability. This provides an operational scheme to chart changes in complexity level in dialogical movements.

\section{Illustration}

We may explain the operationalization of these principles with an illustration. For this purpose, we choose a rather common problem found among Asian students attending prestigious institutions: the coexistence of arrogance and poor self-esteem, which impedes learning. (In the case of lowranking institutions, students’ poor self-esteem is exacerbated.) As university teachers in Asia, we are confronted with this problem on a daily basis. A relational conception of selfhood would eschew viewing it simply as a 'personality' problem, located within the student. Rather, it would favor attending to the student's internal dialogue, followed by inviting him or her to engage in external dialogues with therapeutic others and in constructive actions. In the following, we report a partial distillate of dialogical movements we have witnessed. We use the word student in a generalized sense, exemplary of a class of similar cases.

First, positioning: the student reports his initial internal dialogue. Learning from the summation of experience leads to an awareness of a personal problem, and awareness is the mother of change. Our annotations about levels of complexity are enclosed in brackets.

Being admitted to a top-ranking university means that people outside think you must be terribly smart [perceiving other people's perception of oneself, L2]. But, in actuality, I have a low opinion of myself [self-perception, L1]. So, 
like other students around me, I have to act as if I am smart, even arrogant [perceiving one's social self, L1]. All this makes me uncomfortable [perceiving one's emotional discomfort, L1].

Next, counterpositioning: the student expresses different voices during participating in therapeutic external dialogues-with a sense of humor. We would expect here more self-reflections and more perspective-taking, and hence an increase in higher-level perceptions.

Perhaps I have been too heavily influenced by what other people think of myself [reflecting on perceiving how others perceive oneself, L3]. Let them think what they think, can't change that anyway [certain things can't be changed, L1]. So let me revel at the thought that people are dumb to think I am smart [reflecting on thinking about others' perception of oneself, L3]. . .. But do I have to act smart, and be untrue to myself [reflecting on one's judgment of being untrue to oneself, L3]? I laugh when I think of how some people think I have an inflated ego-unaware that, deep down, I feel rather inadequate [reflecting on perceiving how others perceive one's self-perception, L4].

Finally, repositioning: the student shows greater awareness of his self in relation to others, with a hint of being kinder toward both. He begins to assume personal responsibility and appreciate the value of taking constructive actions. To be aware of one's lack of awareness is to know one's ignorance, amounting to a significant gain in knowledge. Achieving a measure of reintegration is in sight.

We have been at the mercy of what other people expect of us [perceiving reactions to others' expectations, L2]. We don't have to act smart [expressing freedom of action, L1]. ... I don't like the fact that I think so poorly of myself [reflecting on one's self-concept, L2]. If the opinions of others don't help, I have to change my own opinion [expressing personal responsibility, L1]. That means I have to do something positive, like bettering myself as a person [taking constructive action, L1].. .. Perhaps I have been too harsh in judging myself and others [reflecting on one's harshness, L2]. .. . It's ridiculous, so many things we didn't know before [awareness of one's ignorance, L2].

\section{Conclusion}

The convergence in relational constructions of the self in the East and the West is a symptom of the contemporary Zeitgeist-shifting from individualism to relationalism. Increasingly notions of the autonomous self and of the mind as an individual thing are being questioned. Selfhood and mind now tend to be seen as products of joint collaboration between self and others - a theme that may be discerned in successive issues of Culture \& Psychology. In this context, constructions of the dialogical self offer one of the most exciting possibilities to 
capture more faithfully than hitherto the human potential for self-creation and selftransformation.

\section{Notes}

The authors gratefully acknowledge support for the present study from the Department of Psychology, University of Hong Kong.

1. Chinese names are spelled according to pinyin romanization; Wade-Giles romanization is given in parentheses at their first occurrence.

\section{References}

Bain, B. (1996). Pathways to the peak of'Mount Piaget and Vygotsky: Speaking and cognizing monologically and bilingually Rome: Belzoni Editore. Bakhtin, M.M.

(1973). Problems of Dostoevsky's poetics (2nd ed.; R.W. Rotsel,

Trans.). Ann Arbor, MI: Ardis. (Original work published 1929) Cooley, C.H.

(1964). Human nature and the social order. New York: Schocken.

(Original work published 1902) Hermans, H.J.M. (1999). Dialogical thinking and

self-innovation. Culture \&

Psychology, 5(1), 67-87. Hermans, H.J.M. (2001a). The dialogical self: Toward a theory of personal and

cultural positioning. Culture \& Psychology 7(3), 243-281. Hermans, H.J.M.

(2001b). The construction of a Personal Position Repertoire:

Method and practice. Culture \& Psychology, 7(3), 323-365. Hilgard, E.

(1949). Human motives and the concept of the self. American

Psychologist, 4, 374-382. Ho, D.Y.F. (1988). The conception of human nature in

Mao Tse-tung Thought.

In A.C. Paranjpe, D.Y.F. Ho, \& R.W. Rieber (Eds.), Asian contributions to psychology (pp. 235-250). New York: Praeger. Ho, D.Y.F. (2000). Dialectical

thinking: Neither Eastern nor Western. American

Psychologist, 55, 1064-1065. Ho, D.Y.F, Peng, S.Q., Lai, A.C., \& Chan, S.F. (in

press). Indigenization and

beyond: Methodological relationalism in the study of personality across cultural traditions. Journal of Personality. Krauss, R.M., \& Chiu, C.-Y

(1998). Language and social behavior. In D.T

Gilbert, S.T Fiske, \& G. Lindzey (Eds.), The handbook of social psychology (Vol. 2; 4th ed.). Boston, MA: McGraw-Hill. Paranjpe, A.C. (1998). Self and identity in modern psychology and Indian thought.

New York: Plenum. Valsiner, J. (2000, June 23-26). Making meaning out of mind: Self-less and self-ful

dialogicality. Presentation at the First International Conference on the

Dialogical Self, Nijmegen, The Netherlands.

\section{Biographies}

DAVID YAU-FAI HO is presently Senior Fellow at the National Institute of Education in Singapore and Honorary Professor at the University of Hong 
Kong. He is committed to the enrichment of mainstream psychology derived from the intellectual traditions of Asia. His current interest is to explicate methodological relationalism, a general framework for the analysis of thought and action. Professor Ho is the author of numerous contributions in psychology, psychiatry sociology and education. He has had multicultural experiences in North America, Hawaii, the Philippines, Taiwan and mainland China. He was formerly President of the International Council of Psychologists. ADDRESS: Prof. David Y.F. Ho, Psychological Studies Academic Group, National Institute of Education, 1 Nanyang Walk, Singapore 637616. [email: yfdho@nie-edu.sg]

SHUI-FUN FIONA CHAN is Assistant Lecturer in Psychology at the University of Hong Kong. Her current projects concern practical intelligence as a factor in job success, intrinsic learning motivation of children, second-language acquisition of bilinguals, cultural aspects of consumer behavior, and applications of methodological relationalism.

SI-QING PENG is an Assistant Professor at the Guanghua School of Management of Peking University, and will be a visiting scholar at the Kellogg Graduate School of Management of Northwestern University until September 2001. He received a Ph.D. in social psychology from the University of Hong Kong. His research interests focus on consumer behavior, cultural marketing and the psychology of Chinese people.

AIK KWANG NG did his postgraudate studies at the University of Queensland in Australia. He is currently Assistant Professor at the National Institute of Education in Singapore. He is interested in how culture influences creative behavior. He has recently published a book on this topic, entitled Why Asians Are Less Creative than Westerners (Prentice-Hall, 2001). 